\title{
O.S.P.
}

L'orientation scolaire et professionnelle

$29 / 4 \mid 2000$

Varia

\section{M., Maruani. Travail et emploi des femmes.}

Paris : La découverte

Françoise Vouillot

\section{CpenEdition}

Journals

Édition électronique

URL : http://journals.openedition.org/osp/5811

DOI : 10.4000/osp.5811

ISSN : 2104-3795

Éditeur

Institut national d'étude du travail et d'orientation professionnelle (INETOP)

Édition imprimée

Date de publication : 15 décembre 2000

ISSN : 0249-6739

Référence électronique

Françoise Vouillot, «M., Maruani. Travail et emploi des femmes. », L'orientation scolaire et

professionnelle [En ligne], 29/4 | 2000, mis en ligne le 22 mai 2018, consulté le 22 octobre 2020. URL

http://journals.openedition.org/osp/5811 ; DOI : https://doi.org/10.4000/osp.5811

Ce document a été généré automatiquement le 22 octobre 2020

(c) Tous droits réservés 


\section{M., Maruani. Travail et emploi des femmes.}

Paris : La découverte

Françoise Vouillot

\section{RÉFÉRENCE}

Paris : La Découverte, coll. Repères.

1 M. Maruani, spécialiste reconnue de l'analyse sociologique de la division sexuée du travail, offre dans son ouvrage ici les contours du travail et de l'emploi des femmes.

2 La première partie présente en termes d'évolution et de transformations les caractéristiques de l'activité féminine au cours de ces 40 dernières années : la progression constante du taux d'activité et sa résistance aux crises de l'emploi, la féminisation et la tertiarisation du salariat, les modifications du rapport à l'emploi et des comportements d'activité féminins. Ces mutations sont mises en regard de ce qui se passe en amont du côté de l'école, où la progression des scolarités féminines est très sensible depuis le début des années 70.

3 Malgré l'élévation du niveau d'instruction des filles, la féminisation de la population active, la législation sur l'égalité professionnelle, force est de constater que le monde du travail n'est pas mixte et que les inégalités entre hommes et femmes perdurent.

4 La seconde partie de l'ouvrage fournit une description fine de ces disparités : la nonmixité du monde du travail est caractérisée par une concentration des emplois féminins, par une ségrégation verticale et horizontale des emplois masculins et féminins. On assiste en outre à un phénomène de bipolarisation de la population active féminine. Une partie des femmes parvient à rentabiliser son investissement scolaire, alors que la majorité est encore concentrée dans le salariat d'exécution. L'auteure pose ensuite les questions (récentes dans le champ de la sociologie du travail) : comment se produisent les inégalités et sur quoi se fonde la division sexuée du travail ? Trois 
facteurs sont invoqués : les rapports entre travail et travail domestique, les rapports sociaux de sexe et la construction sociale de la qualification.

5 La troisième partie est consacrée au chômage et aux inégalités entre les sexes qui le caractérisent. M. Maruani dénonce en particulier la tolérance politique et sociale au sur-chômage des femmes qui renvoie au problème de la légitimité du travail féminin

6 Enfin, la dernière partie décrit et analyse le travail à temps partiel dans le fonctionnement $d u$ marché du travail et ses conséquences sur les carrières et qualifications, sur la production de sous-emplois et sur l'appauvrissement du salariat féminin.

7 Dans chacun des quatre chapitres des statistiques et des études de cas, illustrent et soutiennent les propos, ce qui rend la lecture et l'appropriation des analyses accessibles aux lecteurs non spécialistes.

8 On retrouve dans cet ouvrage la rigueur intellectuelle, le ton direct, et l'engagement d'une chercheuse qui refuse le " politiquement correct " et qui a permis le développement de la réflexion sur les inégalités de sexe dans le travail.

9 Après avoir lu ce livre, on ne peut plus rester dans le confort de l'idée que l'organisation et le fonctionnement sexués du marché du travail sont le produit d'un ordre "naturel ", et il engage chacun et chacune dans une réflexion sur la place des hommes et des femmes dans la société. 